\title{
En torno a la ordenación espacio-temporal del relato en Solitud de Víctor Català y Cosima de Grazia Deledda
}

\author{
ÓSCAR FERnÁNDEZ PoZA
}

(UCM)

I. En estas páginas intentaremos, en primer lugar, constatar la presencia en el espacio narrativo de los ejes vertical y horizontal que ordenan el relato, así como la proyección de los verbos de movimiento y de los indicadores de espacio sobre estos ejes.

Los diccionarios sobre términos literarios hablan del espacio como una noción tridimensional (alto, ancho y profundo). ${ }^{\prime}$ Esta definición, a la hora de aplicarla a Solitud (1906) de Caterina Albert i Paradís - Víctor Català -, permite dividir sus espacios en dos ámbitos, un espacio exterior donde encontramos las representaciones físicas y geométricas del mundo, y un espacio interior que correspondería, como dice Samuel Alexandre, al espacio mental de los personajes. Según este criterio, estos dos niveles de espacios pertenecen a un espacio que en parte es contemplado, en parte gozado. ${ }^{2}$ Por lo tanto el espacio contemplado puede ser condicionado por el espacio mental.

No podemos olvidar la relación existente entre el espacio y el tiempo, porque sin el uno ni el otro difícilmente puede haber narración. Hay una relación indisoluble, no se puede romper la unión entre estas dos coordenadas narratológicas. Esta relación entre las dos coordenadas nos haría pensar que la primera novela aquí tratada tiene una estructura circular, que claro que la tiene, más aún cuando se puede considerar como una novela de iniciación, porque Mila intenta la búsqueda de dos elementos: la conquista del espacio que la rodea y del amor por parte de la protagonista; y el descubrimiento de la verdad de su existencia y de la gente que tiene a su alrededor. Esta búsqueda puede llevar al conocimiento de Dios y del Diablo, del bien y del mal, o a vivir su embate, tópico de atracción finisecular, en el arte y las letras entre el ochocientos y el novecientos.

1 «...es una extensión. (...) tridimensional en que los objetos ocupan posiciones» - R. Gullón, «Espacio Novelesco» en: G. Gullón y A. Gullón, Teoría de la Novela, Madrid, Taurus, 1974, p. 243.

2 «...nuestro espacio mental y nuestro espacio contemplado pertenecen experimentalmente a un Espacio que en parte es contemplado, en parte gozado. Todos los objetos físicos son aprehendidos alli, en relación espacial con nuestro propio espacio con otro espacio mental». Samuel Alexandre, «Time and Deity», Dover Publications, New Cork, 1960, citado por G. y A. Gullón. Teoría de la Novela, p. 243. 
La estructura de la novela de Caterina Albert i Paradís se inicia en un punto, con la subida de la protagonista a la ermita como recién casada e inocente, y finaliza con el descenso de la ermita, por el mismo camino, convertida ya en una mujer que sabe muy bien lo que quiere hacer con el resto de su vida. Pero la autora no deja la novela cerrada en este punto, sino que, en sus últimas líneas, en el diálogo final de Maties y Mila, deja abierta la puerta para un futuro, el tiempo que impone la continuación de la propia biología de la protagonista:

«Vegent que no obria boca, ella li signà l'ermita.

- Ara, ja t'ho deus pensar... Jo, allà dins, mai més...' Però no he volgut anar-me'n sense dir-t'ho...

El rostre cadavèric d'ell es desencaixà absolutament sota l'acció d'aquelles noves paraules.

—Què! ... - -murmurà d' una veu aterrada-. ¿Te'n vols anar? A on...? (...)

Les filtracions de la solitud havien cristal-litzat amargament en son dest'i (pp. 312-313: 54-86; tr. pp. 187).

Al tener, con todo, una estructura circular, creemos ver un predominio del eje vertical sobre el horizontal. Este eje vertical se encuentra potenciado por la presencia de la otra coordenada narratológica: el tiempo. El tiempo también es circular, ya que pensamos que la obra comienza en otoño («...i com ja no feia calor», cap. I, pp. 58: 483; tr. 16) y acaba también en otoño, pero a finales de este («...malgrat fos del món empestat de la taverna on hivernava», cap. XVI, pp. 287: 91-92; pp. 170). Es decir, la presencia de un tiempo tan reducido, más o menos de un año, provoca que en el eje horizontal, que se prolonga a lo largo del relato, aparezca y tome relevancia el eje vertical. Así que todas las acciones y hechos que son reflejados en la novela se encuentran en este tiempo, y hacen que el eje vertical sea más importante que el otro. De este modo todas las ascensiones y los descensos dentro de la obra tomarán una trascendencia mayor que si se prolongasen más los hechos narrados en el tiempo.

Dentro de la novela podemos observar las diferentes estaciones del año, a partir de varias partículas temporales como los meses o los nombres de las estaciones. Incluso se podría identificar días exactos en que transcurren algunos capítulos como puede ser el caso de los capítulos VIII y IX (La festa de les roses y Gatzara) que sería el día 11 de mayo coincidiendo con el día de Sant Ponç, fiesta muy celebrada en Cataluña de acuerdo con la información del folclorista Joan Amades. ${ }^{3} \mathrm{O}$ el día de la «festa petita de Murons» (cap. XVII, La nit aquella, p. 298: 1-2; tr. p. 177), que no hemos podido identificar con ninguna fecha concreta de las fiestas de la comarca donde transcurre la novela y que muy bien debiera conocer la autora.

Señalaremos asimismo que los cuatro primeros capítulos, en nuestra opinión, corresponderían al otoño, como se puede observar en la siguiente referencia que se da en el texto: «ja no feia calor» (cap. I, p. 58: 483; tr. p.16). A lo largo de los capítulos V y VI nos encontraríamos en el invierno. Ya en el capítulo

3 Vid. J. Amades: Costumari català: el curs de l'any, Barcelona, Edicions 62, 1982, vol. III, pp. $587-590$ 
VII (Primavera) no solamente por el título del capítulo sino también por la afirmación en sus primeros párrafos del texto, nos situamos en los primeros días de mayo: «Els primers dies de maig...» (p. 144: 1; tr. p. 73).

Como ya hemos dicho, los capítulos VIII y IX transcurrirían en el día 11 de mayo, y siguiendo el esquema temporal que ha propuesto Víctor Català el capítulo X, Reliquias, y XI, Mal de Muntanya, corresponderían al verano. Como podemos ver en la primera frase del capítulo undécimo: «L'estiu hauria passat lànguid o cruel per a la Mila, si no l' hagués distreta una mica la gent que durant tot ell pujà sovint a l' ermita" (cap. XI, p. 192: 1-3; tr. p. 105). O teniendo presente una referencia que aparece más adelante, que se encuentra en «les derreries d'agost» (p. 193: 48; tr. p. 106).

A la mitad del mencionado capítulo, Caterina Albert comienza la transición de una estación a otra, de verano a otoño, que se completaría con el capítulo XII, Vida enrera. En el capítulo XI tenemos las siguientes referencias a este paso:

«Amb la baixada de l'estiu...» (p. 196: 154; tr. p. 108).

«Pel setembre, en què el sol cremava encara en les clotades al bon cor del dia, però que les ombres començaven a ésser traspasades per vents aćanalats, plens de males resultes,..." (p. 196: 156-160; tr. p. 108).

«Finava l'octubre i els crepuscles, fent sempre més i més lloc a la nit, retallaven da cada cap el dia amb estisores d"ombra,...” (p. 201: 328-330; tr. p. 111).

Y los últimos capítulos corresponderían al final del otoño y principio del invierno, como se puede entender por la expresión empleada en diferentes momentos como es la de «hivernada» (cap. XIII, p. 222: 2; tr. p. 125).

El tiempo tan condensado y lo que significan las dos ascensiones simbólicas que ocurren en la novela permiten hablar del predominio del eje vertical en Solitud, pero no podemos olvidarnos del eje horizontal que asimismo condensa. Su reflejo lo podemos encontrar en las diferentes descripciones que Víctor Català realiza a lo largo del texto, por ejemplo en la visión que tiene Mila del valle de Ridorta durante la primera ascensión hacia la ermita:

«De l'altra banda, i a cosa de cana i mitja per sota la carretera, s'estenia el pla de Ridorta, abraçat al turó $i$ tot ell divís en partions simètriques, mateix que un gran tauler d'escacs.» (cap. I; p. 45: 51-54; tr. p. 8).

El predominio del eje vertical no sólo se puede ver en la evolución del personaje de Mila y de los hechos que la rodean, sino que también se puede observar en los diferentes verbos de movimiento y lugares que recorren los personajes. Estas ascensiones y descensos dentro del eje vertical no se centran exclusivamente en las dos ascensiones significativas que se encuentran en la novela, la primera a la ermita y la segunda al Cimalt, sino que también hallamos este movimiento de subida y de bajada dentro de la casa, siendo, en este caso, el más significativo el episodio de la violación (cap. XVII, pp. 301-304: 131-230; tr. p. 179-181), ya que establece un continuo movimiento dentro de un núcleo cerrado que a su vez alberga un espacio sagrado. 
Durante la primera ascensión a la ermita, que se encuentra en el capítulo I de la novela (La pujada), predomina como hemos ido diciendo el eje vertical, principalmente la coordenada de subida y crecimiento, ya que no solamente comienza el viaje a la ermita, sino que también se inicia el periodo de aprendizaje y de iniciación de Mila (cap. I, pp. 45: 62-69; tr. p. 8), una Mila inocente y sin conocimiento de la vida, como se puede ver en este camino hacia la ermita, caminando ingenua por detrás de su marido (cap. I, p. 43: 4-8; tr. p. 7).

A lo largo de este primer capítulo tenemos muestras de los diversos recursos que emplea Caterina Albert para marcar el ascenso y descenso (coincidiendo con los que se encuentran también a lo largo de la novela): verbos de movimiento que nos van marcando el ascenso de la pareja de recién casados hacia la ermita, como pueden ser «caminaven» (p. 43: 13-14; tr. p. 8), «pujaré» (p. 49: 189; tr. p. 9), etc.; pero no sólo con los verbos se nos va indicando este movimiento ascendente sino también con la mención de los diferentes nombres de los pueblos que se ven mientras se va cobrando perspectiva del horizonte como «Ridorta» (p. 56: tr. p. 15); o parajes que se encuentran en aquella subida: «la Canal» (p. 51: 52; tr. p. 11), «els Roquis» (p. 55; tr. p. 14), «Torrent de Mala-Sang» (p. 59: 541; tr. p. 17); y por último, mediante la propia descripción del camino:

«De cop el camí es retorçà en colzada violent i s'adreçà enlaire com si anés a saltar un obstacle.» (p. 54: 337-338; tr. p. 13).

«Allò no era un camí per a persones de Nostre Senyor, sinó per a cabres ofacinerosos» (p. 54: 367-369; tr. p. 14).

Probablemente se va dando no sólo la sensación de ascensión sino de dificultad en la subida, lo que no viene agravado por el tiempo meteorológico, ya que según la autora era un día que «...no feia calor» (p. 58: 483; p. 16).

Con la conclusión del primer capítulo entramos en un bloque de capítulos donde predomina el eje horizontal, que estaría formado por los capítulos II, III y IV. Estos capítulos tienen como elemento unificador la ermita, y es a su alrededor donde gira toda la actividad. Accedemos a unos capítulos donde Mila comienza el reconocimiento del mundo que la rodea, el descubrimiento del espacio. Pero a su vez, Mila sube y baja por la ermita, son movimientos verticales que no rompen el predominio del eje horizontal. Mediante ellos conocemos la distribución de la casa y de las diferentes partes que la componen como el patio:

«A la poca claror del fanalot vegé incertament un pati enrodat d'altes parets $i$ enganxat a una casa; enmig del pati hi discobri el brocal d'un pou, amb el pouador de ferro tot enguerxat; al fons, una gran arcada rompia la paret de la casa, $i$ al costat de l'arcada, en l'angle del pati, hi havia una escala de pedra picada...» (cap. II, p. 63: 75-82; tr. p. 19).

O la posterior descripción de la casa: «...dels alts, era la cuina i dels baixos la capella» (cap. IV, p. 92: 19-20; tr. p. 38). También observamos a través de los verbos como se mueve Mila, así como sus acompañantes: «entrem» (cap. II, p. 66: 168; tr. p. 21), «baixà» (cap. II, p. 68: 230; tr. p. 22), «sortiren» (cap. II, p. 71: 334; tr. p. 24), «...havien pujat a la cuina» (cap. III, p. 79: 159; tr. p. 30), 
«...després tornaren a baixar» (cap. III, p. 79: 161; tr. p. 30), «...baixà de l'altar» (cap. IV, p. 94: 91; tr. p. 40), «...passant pel pati, se' $n$ va anar» (cap. IV, p. 96: 161; tr. p. 41), etc.

Se trata en este caso de un movimiento desenfrenado, ya que se mueve por toda la casa reconociéndola y limpiándola, pero siempre con el predominio del eje horizontal, porque va de una habitación a otra, aunque encontramos verbos y partes de la casa que nos indican que sube y baja. Todo este movimiento de Mila dentro de la ermita, no cobra sentido en este momento en la novela, pero ya hacia el final tenemos otro episodio con estas mismas características. Reaparecerán los mismos espacios, donde encontramos un número de verbos de movimiento que nos están modificando la visión del eje predominante del texto, del eje horizontal que tenemos en estos capítulos al eje vertical. Nos referimos a la violación (cap. XVII, pp. 301-304: 131-230; tr. p. 179-181).

Durante el bloque formado por los capítulos $\mathrm{V}$ al XII, no podemos indicar cual es el eje predominante en el texto, ya que si atendiéramos a los verbos de movimiento no podríamos decantarnos por uno u otro, porque su número y significado son escasos, sólo pudiendo destacar los capítulos VIII y IX (La festa de les roses y Gatzara) donde tenemos un predominio del eje vertical, ya que hallamos una gran agitación para la preparación de la fiesta (p. 158: 166 o p. 160: 257 ; tr. p. 81 o p. 84 ), y encontramos la referencia a la primera vez que baja Mila por el camino que realizó en la primera ascensión a la ermita (cap. VIII, p. 153: 1-6; tr. p. 79). Esta bajada vuelve a confirmar que el camino era muy duro y peligroso («...tresqueres de tan mal pujar» p. 154:20; tr. p. 79), pero también que la bajada se hacía en un «pensament», como se refleja en las palabras de Maties:

«...A la baixada, les cames no poden aturar-se i el camí dura un pensament» (cap. VIII, p. 154: 21-22; tr. p. 79).

En el resto de capítulos que formarían este bloque sería indefinido el eje vertical u horizontal, si atendemos a los verbos o los indicadores de espacio, pero si nos fijamos en el contenido y en la búsqueda de Mila, en la iniciación de esta por parte del Pastor, del descubrimiento de la verdad de su existencia, debemos hablar del predominio del eje vertical, ya que se inicia su aprendizaje que llegará a su punto álgido en el capítulo XIV (En la creu) donde se le revelará el conocimiento no sólo del mundo que la rodea, sino del amor y de la vida de engaño en que vive.

El bloque final de capítulos en que podemos dividir la novela de Víctor $\mathrm{Ca}$ talà, se podría subdividir en dos nuevas partes, la primera sería la formada por los capítulos XIII y XIV (El Cimalt y En la creu), que llevaría al camino culminante, como hemos dicho antes, de los capítulos anteriores; y la segunda conformada por los capítulos finales de la obra (cap. XV al XVIII), donde no sólo tenemos el desenlace final de Solitud, sino que se encuentra la bajada final a los infiernos por parte de Mila con la violación, siendo el capítulo XIV la subida a los cielos, afirmación que alcanza con la búsqueda que conducirá al conocimiento de Dios y del Diablo. Al mismo tiempo contaríamos también con la bajada final de la ermita y el abandono del mundo que ha conocido hasta entonces. 
En el capítulo XIII, la autora utiliza las mismas técnicas que había empleado en el capítulo primero para ir marcándonos la subida, es decir, los verbos de movimiento: «...caminaven en silenci» (p. 227: 192-193; tr. p. 128), «...tornaren a caminar» (p. 236: 512; tr. p. 134), etc.; el empleo de los nombres de lugar: «la Gorga de les Tres Pintetes» (p. 228: 234; tr. p. 129), «Clot del Pas de Llamps» (p. 229: 259; tr. p. 130), «Fita dels Moros» (p. 233: 394; tr. p. 132), «els Roquisos» (p. 236: 515; tr. p. 134), y la descripción del camino:

«... tornaren a caminar per la dreta pendent, fent ziga-zagues, ara endavant, ara com si retornessin sobre sos passos, mes pujant, pujant, pujant sempre. I a mida que pujaven, els Roquisos creixien i s'eixamplaven, descobrint a cada pas a la dona encuriosada tots els llocs de que li havien fet esment $i$ donat coneixença les rondalles del pastor» (p. 236: 512-519; tr. p. 134).

Esta ascensión al Cimalt no es tan dura y peligrosa como lo es a la ermita, ya que Mila está disfrutando de ella en compañía del Pastor, su guía en la búsqueda del conocimiento. Helena Alvarado ${ }^{4}$ dice que la ascensión significa también una ascensión de conocimiento. A lo largo de la conversación que tienen, Mila quiere aprender todo sobre el mundo que le rodea, conseguir el entendimiento del medio, como se ve en la siguiente conversación:

«Aleshores la Mila s'aturà un punt per a preguntar: fet ara?

-Digueu, pastor: per a anar amunt ¿no hi ha altre cami que el que hem

-Certus que sí!. Tants com ne volgueu. Com que tota la muntanya ho és, camí, podeu agafar-lo per on vos plagui...

(...)

El pastor es posà a riure.

-Ja vos vegi l' intent, a vós!. Voleu aprendre de cor tota la muntanya... _-Això és, això és, pastor...» (p. 241: 681-700; tr. p. 137).

Ese aprendizaje lo concluirá en el siguiente capítulo, con la revelación de algunas de las verdades que Mila está buscando. También se queda sorprendida del paisaje que está viendo mientras está ascendiendo hacia la cima, como se puede ver en una cita anterior o en el resto del capítulo, entre las páginas 242 a 246 (tr. 138 a 141).

En el capítulo XIV, se darían los dos ejes a la vez, es decir, en las primeras páginas del capítulo (pp. 247-252: 1-203; tr. p. 142-144) y las últimas (pp. 265-267: 667-736; tr. p. 154-155) tendríamos evidenciado el eje vertical. Es decir, donde Mila y el Pastor finalizan la ascensión a la cumbre y su posterior bajada de esta hacia la ermita. En esta parte, Víctor Català utiliza las mismas técnicas que ha usado en otros casos para ir marcando la subida, como el empleo de los verbos de movimiento, los nombres de lugar y la descripción de la ascensión:

4 Vid. H. Alvarado: «Solitud» de Víctor Català, Barcelona, Ed. Empúries, 1997, p. 72: «Les ascensions són esglaons de l'escala del coneixement». 
«... Desarem les tovaies $i$ tornarem amunt si vos plau, ... « (p. 249: 65; tr. p. 143).

«Camina que caminaràs, havien arribat d’ una altra bordada quasi bé al currull de Roquís Gros, sense haver deixat mai encara la banda de tramuntana. Vorejaven unes esmotxadures plenes de trencacolls, $i$ aixecant el cap veien ressortir de la muntanya, aplomant-se atrevidament sobre l'estrimbera de salts i pendissos escarpats, les enormes Castelles del Cimalt, la cornisa ferotge de penyarals pelats $i$ rosegats pel temps, que semblava la barbacana runosa de la fortalesa que era el Roquís» (pp. 250-251: 135-144; tr. p. 144-145).

De la misma manera la narradora se vale de idénticas técnicas en el caso del regreso del Cimalt hacia la ermita:

«Començaren de baixar per la banda de llevant. No hi havia un dit de planer en aquell encreuament de venes i regalzes que duien a l'Ull de Corberes, la naixença del collet. En deien, d'aquella baixada, els Relliscalls de la Calavera per unes vetes calisses que de tros en tros els escalonaven, a manera de branilles pelades d'una costellada entètica.» (pp. 265-266: 667-674; tr. p. 154).

Por su parte el eje horizontal abarcaría las páginas centrales del mismo capítulo. En la meseta que se encuentra en la cima, Mila recibe sus últimos consejos de parte del Pastor para concluir su aprendizaje, como sucede a lo largo de la subida y del descenso, así como en capítulos anteriores ha ido aprendiendo la sabiduría natural como hemos visto en una cita anterior o de acuerdo con la siguiente:

«En aquell clap de la muntanya hi creixien bona barreja d'herbes medicinoses que les pageses dels masos coneixien prou bé, recollint-les a son temps amb intent de fer-ne begudes $i$ cataplasmes per a bèsties $i$ persones,...» (p. 266: 674-678; tr. p. 154).

Ya en la cima recibe las enseñanzas religiosas, mediante la narración del Pastor de la «rondalla de la Creu» y sobre las actividades de Maties fuera de la ermita, informándole que es un jugador. Por lo que acabamos de decir, en esta parte del capítulo se están mezclando los dos ejes, pero en niveles diferentes del texto. El eje horizontal lo tenemos constatado en el nivel descriptivo del espacio que encontramos en la cima:

«Estaven en la Creu. Una gran esplanada rocosa coronava el Roquís, escurullant-lo com el gra d'una mesura quan s' hi ha passat el rasador. De moment, la Mila, encarada cap al centre d'aquella esplanada, no vegé més que una estesa de pedregoler sembrat de les invariables mates de garrigues, estepes i romanins» (p. 252: 204-210; tr. p. 146).

«En efecte: el cim enter semblava un alipteri.» (p. 253: 219; tr. p. 146).

«I començaren de donar la volta a l' esplanada.» (p. 254: 274; tr. p. 147).

No solamente desde aquella explanada se puede observar todo el horizonte y los diferentes pueblos y lugares que rodean a la montaña, sino que se alcanza con la vista el mar (pp. 254-255: 274-304; tr. pp. 147-148). 
Asimismo tendríamos en esta parte el eje vertical, aplicado al nivel del contenido. Es decir, Mila va adquiriendo paulatinamente, in crescendo, toda la sabiduría, el conocimiento de la naturaleza y de la condición humana que viene de boca del Pastor. Este último le advierte sobre su marido y a propósito del Ànima. Esta transmisión del conocimiento, en este momento, la recibimos no sólo en referencia a Maties (p. 260 y ss.; tr. p. 151), sino también en la «rondalla de la Creu» (pp. 257-258: 351-409; 148-149).

En el segundo bloque de capítulos (XV al XVIII), el desenlace de la historia, se evidencia el predominio del eje vertical pero en este caso no en su sentido ascendente sino en el descendente, ya que son capítulos que llevan a Mila hacia la bajada hacia los infiernos con la violación, en contraposición con la subida a los cielos en el capítulo XIV, y su marcha definitiva de la ermita, una huida hacia delante.

Antes de llegar al capítulo XVII (La nit aquella) donde se consuma la violación, tenemos dos capítulos que podemos considerar de transición, porque en ellos no ocurre gran cosa, atendiendo al contenido, pero sí, si se atiende a las técnicas empleadas por Víctor Català para la subida y bajada de los personajes. En el capítulo XV no se encuentra referencias que nos indiquen como es la bajada hacia Murons; sólo se dice a propósito de esto que baja por el camino que lleva al mas de Sant Ponç (p. 268: 17-19; tr. p. 156); o contiene la descripción que hace del camino hacia Murons tras la tormenta:

«Després del desgavell del dia ahans, tot, en les altures, havia entrat en caixa, talment com si res hagués passat: (...) sobreixia enverinat $i$ babejava ses aigües llotoses sobre les margeres» (pp. 278-279: 383-398; tr. p. 163).

En el capítulo XVI (Sospites) sólo tenemos reflejado en el texto las intenciones de Mila de bajar a Murons para tener relaciones con la gente, principalmente con Baldiret, y saber algo de su marido.

El capítulo XVII (La nit aquella) se puede dividir en dos partes, predominando en las dos el eje vertical. La primera parte sería la bajada de Mila a Murons durante «la festa petita» (p. 298: 1-2; tr. p. 177). La autora, con la mera mención de que Mila se encuentra ya en el pueblo, se evita repetir y emplear los recursos que en varias ocasiones hemos mencionado, eludiendo la reiteración de este esquema para el descenso. Caterina Albert utiliza este procedimiento para indicar la posterior ascensión hacia la ermita. La segunda parte del capítulo es la violación, que viene influenciada por el tiempo que hacía aquella noche, noche de tormenta en la montaña como puede verse en la descripción que realiza la autora de aquellos momentos, siendo unos instantes de gran movimiento dentro de la casa (pp. 300-301: 73-102; tr. p. 178-179).

Pero es con la violación, cuando la escritora utiliza varios verbos de movimiento, haciendo patente la agitación de Mila y sus movimientos de esta por la casa para poder escapar del Änima, y el posterior recorrido por la ermita para ir cerrando las diferentes ventanas y puertas que están abiertas:

«La dona, al veure-la, havia reculat fins a la paret (...) Perseguida per ell i denunciada (...), passà com un llamp per la cambra del campanar, s'engolí per l'escaleta de la capella (...) 

cala. (...)

Després de molta estona de resta asseguda a terra (...) La Mila pujà l'es-

Entrà a la cuina (...) Entrà en la cambra (...)

La Mila, de dret $i$ sense temença, anà a seure's en un regatell apartat de la solana.» (pp. 301-304: 131-232; tr. p. 179-181).

Con la violación finaliza la iniciación de Mila, que comenzó desde las primeras páginas de la novela, con la subida hacia la ermita. Esta iniciación, en nuestra opinión tendría varias fases que ahora pasaremos a enumerar:

1. La primera ascensión a la ermita, Mila es ingenua y no conoce bien a su marido, Maties, ni el medio que le rodea (cap. I).

2. Primeros pasos de la iniciación, Mila comienza a asimilar las primeras enseñanzas como es el reconocimiento de la ermita, el medio que tiene a su alrededor y las primeras «rondalles» (cap. II al XII). Para Helena Alvarado ${ }^{5}$ la evolución de Mila se plantea como un aprendizaje simbólico por el paso de la oscuridad («foscor») a la claridad («netejada»). No sólo en el conocimiento físico del lugar, de la adicción al juego de su marido, sino de su propia personalidad, que le llevará a la libertad.

3. Finalización de las enseñanzas por parte del Pastor. En este período Mila concluye una primera fase de su iniciación, ya que recibe toda la información necesaria para abrir los ojos al otro mundo, que tenía ante sí misma, pero que no lo quería reconocer (cap. XIII y XIV).

4. Y por último el nacimiento de una nueva Mila. Para que aparezca esta nueva Mila se debe producir la muerte de la antigua. Esta muerte se produce con la violación, hecho traumático que le abre definitivamente los ojos, apareciendo un nuevo ser, con mayor decisión y con nueva personalidad. No soportará las imposiciones sociales que ha sufrido como la indiferencia y las sospechas de la gente ante la supuesta relación con el Pastor, la dejadez de su marido en su relación matrimonial, etc.

Mila ha pasado una serie de pruebas para iniciarse y convertirse en conocedora de sí misma. La violación es un rito que provoca la definitiva muerte de la persona para que aparezca una nueva, y que se pueda decir que ha entrado dentro del grupo de sabios. Como dice la siguiente frase de Mircea Eliade: «El iniciado se transforma en otro hombre por haber tenido una revelación religiosa acerca del Mundo y de la existencia». ${ }^{6}$ En esta frase vemos que se cumplen en gran medida lo que hemos ido diciendo, porque a Mila le es revelado el Mundo y la existencia por parte del Pastor, y se transforma en una nueva persona.

En el último capítulo, como se puede ver por su título, La davallada, Mila se decide a abandonar definitivamente a su marido y la ermita. Como hemos dicho, es una nueva persona, que comienza a tener una personalidad propia y rompe el propio círculo de su existencia. En este capítulo podemos encontrar varios verbos de movimiento que nos indican en principio desplazamiento, pero que se-

"Vid. H. Alvarado: ibid., p. 74: «l'evolució de la Mila es planteja com un aprenentatge simboltizat pel pas de la foscor a la claror".

${ }^{6}$ Vid. M. EliadE: Iniciaciones místicas, Madrid, Taurus, 1975, 1.a ed., p. 17. 
ñalan la intención de Maties de subir hacia la ermita («pujaria» p. 311: 12; tr. p. 186); en cambio otros, marcan la ascensión de este hacia allí: «Pujava apresserat i capbaix,...» (p. 312: 31; tr. p. 186).

Como en un capítulo anterior, Víctor Català no emplea las técnicas que había utilizado en el primer capítulo. Sólo con la mención de que sube le es suficiente. De la misma manera, ocurre con la bajada final de Mila, pero esta se encuentra cargada de una gran fuerza en las palabras y en el significado, ya que Mila abandona un mundo para incorporarse a otro nuevo.

«Després baixà lentament del regatell i sense afegir altre mot, sense tombar la cara, sense res més que la roba de l'e squena, la dona, èrtica i greu, amb el cap dret $i$ els ulls ombrivols, emprengué sola la davallada» (p. 313: 80-84; tr. p. 187).

Jordi Castellanos considera que el libro de Víctor Català es una «novel.la tancada», que no hay un futuro en el horizonte. Merced a la oposición llano«no-vida» y montaña-«vida», términos que emplea Castellanos dos páginas más adelante:

«...dues formes de vida antitètiques: una, la de la plana, despersonalitzada, utilitarista i monòtona; l'altra, la de la muntanya, intensa, misteriosa i plena de sorpreses de tota mena. En realitat, es trata de la confrontació entre «no$v i d a »($ plana) $i$ «vida» (muntanya)».?

En nuestra opinión ese orden se invierte al final de la novela tras la violación sufrida por Mila. La protagonista decide marcharse del ambiente que le rodea en la montaña, y que ha significado hasta entonces vida, conocimiento, a la llanura que en nuestra opinión tiene el significado de una nueva existencia, una nueva realidad, que ella deberá descubrir por sí sola, sin la ayuda de nadie. Y por lo tanto, creemos que la novela se puede considerar abierta pues hay una voluntad de un nuevo conocimiento y reconocimiento del ser humano y de las relaciones en comunidad.

II. Respecto a lo desarrollado sobre la ordenación espacio-temporal y el dominio de uno u otro eje (horizontalidad/ verticalidad), buscaremos un ejemplo contrastivo en una novela de unas décadas más tarde y de otra literatura, la italiana. En cualquier caso, somos de la opinión de que no nos iríamos demasiado lejos en ningún sentido y de que nos mantenemos inmersos en un ciclo histórico-literario que presenta ciertas constantes a lo largo de su cronología, permitiendo unas mismas pautas de lectura. Téngase presente además que la escritora a la que nos vamos a referir comienza su obra en el marco del Decadentismo italiano correspondiente con el Modernisme en el que se enmarca Víctor Català. ${ }^{8}$ Nos referimos

${ }^{7}$ En «Solitud, novel-la modernista», Els Marges, 25, 1982, pp. 45 y 47.

${ }^{8}$ El Decadentismo italiano, según los rasgos que retoma la historiografía itálica, coincide con el perfil histórico-literario del Modernismo catalán, entre los últimos decenios del siglo XIX y los primeros del siglo xx (vid. por ej. G. PETRONIO: Historia de la Literatura Italiana, traducida por M. Carrera y M.a de las N. Muñiz, Madrid, Cátedra, 1990, pp. 824-826 y 853). Puede asimismo tenerse en cuenta la utilización del encuadre costumbrista o de la perspectiva regionalista que en ocasiones tienen en cuenta los críticos en torno a nuestras autoras, aspectos que pudieran abrir otros niveles de lectura comparada sobre sus textos. 
a Cosima (1937) de Grazia Deledda, título y autora que seguirán el esquema de los ejes horizontales y los ejes verticales para la ordenación del relato que hemos presentado anteriormente en Solitud. ${ }^{9}$ Pero en este nuevo caso, encontramos un predominio del eje horizontal sobre el vertical. Por esta razón ambos títulos presentan relaciones divergentes, al tiempo que tienen, así mismo, un punto en común, la presencia del viaje y su función estructuradora del relato, en relación con el Bildungsroman, de presencia común en la literatura europea de aquellas décadas.

En Cosima, que fue publicada póstumamente, ${ }^{10}$ predomina como queda dicho, el eje horizontal sobre el vertical, ya que las acciones y los espacios descritos están situados en un plano geográficamente elevado, su ciudad natal, Nuoro, donde vivió Deledda, y donde se desarrolla la trama del relato. La novela se puede considerar como un ejercicio de proyección autobiográfica porque muchos de los aspectos y temas que se tratan los ratifica la vida de la escritora, comenzando por el título de la obra que corresponde a su segundo nombre, pues en realidad se llamaba Grazia Cosima Deledda. Nuoro, especifiquemos, se encuentra situada en una meseta en el centro de la isla de Cerdeña, en la región de Barbagia, donde autora y personaje vivirán hasta su marcha a Roma.

Como ya hemos dicho a lo largo de estas páginas, en Solitud hay una ascensión previa antes de situarnos en el eje horizontal, en la ermita; en Cosima, las acciones, los espacios y los personajes ya se encuentran en el eje horizontal - aunque también hay una ascensión puntual a una ermita en la montaña-y sólo por último se realiza un descenso hacia la costa, remitiendo a como Deledda, en su biografía, llega a Calgliari para marcharse de la isla hacia Roma, tras conocer a su futuro marido; este deseo de irse de la isla es patente en la obra, apareciendo así la oposición Isla vs. Ciudad, representando un contenido importante para el relato.

${ }^{9}$ Estas dos novelas ya han merecido una lectura comparada en esta misma publicación, atendiendo a otros niveles de composición de los textos; vid. E. ARTEAGA: «Caterina Albert y Grazia Deledda: Aproximación al tema de la mujer en su novelística», Revista de lenguas y literaturas catalana, gallega y vasca, 1996-1997, vol. V, pp. 17-27.

${ }^{10}$ Resumiendo la información que aparece en la nota de los editores de Cósima en Espasa-Calpe de 1946, pp. 9-10, podemos decir que Grazia Deledda cuando pudo comenzar a escribir, ya hacía tiempo que tenía in mente esta obra. En 1931 comenta a Pietro Panerazi que había comenzado a escribir unas memorias, y éste se las pidió para su revista. Pegaso. Deledda en estos momentos no sabía como iba a tratar este tema, de manera directa o fingiéndola en el plano de la narración objetiva. Probablemente tal perplejidad debió aún durar en ella por algún tiempo; y entretanto, se dedicó a otros trabajos, en los cuales, según había hecho siempre, insertó todo aquello que por ser autobiográfico convenía al asunto. En otoño de 1934 sufre una enfermedad grave y como consecuencia una larga convalecencia. Se ignora si hacia esta época habría comenzado ya las primeras páginas de la novela. Pero a mediados de 1936 se vio obligada a atender otros trabajos, escribiendo novelas breves para el Corriere de la Sera. Tras su muerte en Roma, el 15 de agosto de 1936, el director de la Nuova Antologia, revista donde colaboró la autora hasta 1898, se informó de las cartas que había dejado; y los familiares entregaron para su examen las carpetas del único manuscrito de Cosima. Tal obra, a la que le faltaba el título y la palabra fin, vio la luz en tres fascículos de la revista ( 16 de septiembre a 16 de octubre). La primera entrega, para advertir rápidamente a los lectores del carácter singular de la narración, se tituló Cosima o Grazia; las sucesivas entregas aparecieron ya con el título de Cosima. 
Como en Solitud, el predominio de un tipo de eje viene influido por el tiempo. En Cosima el tiempo potencia la preeminencia del eje horizontal, porque el desarrollo temporal del relato es más amplio, de modo que corresponde a su existencia vital. Va, en ese segundo caso, desde el nacimiento de una de sus hermanas, Beppa, hasta su marcha definitiva a la costa (Cagliari), transcurriendo más o menos quince años. De este modo las apariciones del eje vertical pierden la consistencia que tendrían si el tiempo fuera menor o más condensado. Recuérdese que en la obra de Català el tiempo cronológico en que está encuadrada la novela es mucho más corto pues no va más allá de un año. Recuérdese asimismo que, como hemos reseñado al principio, se podría situar el comienzo de la novela en otoño y concluiría un año más tarde, casi ya en el invierno, conteniendo un simbólico ciclo estacional.

Como hemos dicho, en la novela de la escritora sarda predomina el eje horizontal. Tenemos en ella un gran número de espacializaciones en este nivel, pudiendo calificarlas de cotidianas, ya que pertenecen al día a día de la sociedad sarda y son representativas de la vida de una comunidad y de sus tradiciones. A diferencia de la novela catalana — donde los espacios simbólicos se ubican en el eje vertical-, en la obra de Deledda encontramos en ocasiones espacios del eje horizontal que son modificados por la visión del personaje principal de la obra, tomando un valor simbólico. Ejemplos de este tipo de espacio modificado serían la visión por parte de Cosima de la habitación de sus padres tras el nacimiento de su hermana, su visión sobre la escuela, o la librería del señor Carlino. A continuación insertaremos dos textos donde podemos observar estas modificaciones:

«Si trovo nella camera, dietro di lui, e rivide le note cose: il letto grande con una sopracoperta di percalle a fiori, l' armadio, la "consolle" di noce, che era il mobile piú elegante della casa, i quadri il caminetto bianco: ma tutto le parve mutato, come se una luce di miracolo avesse dato alle cose un aspetto diverso, d' incantamento, come quando si vedono riflesse nell' acqua od anche sui vetri spalancati di una finestra; e quel riverbero si spandeva da un centro straordinario: da un canestro di asfodelo, deposto sulla pietra del camino, $e$ dove, fra cuscini e pannolini, stava la neonata.» (p. 15; tr. p. 58).

«...ma quella che piú interessa la nostra scolaretta è la librería del signor Carlino, dove si vendono i quaderni, l'inchiostro, i pennini; tutte quelle cose magiche, insomma, con le quali si può tradurre in segni la parola, e piú che la parola il pensiero dell' uomo.» (p. 30; tr. p. 72).

Otro espacio en el eje horizontal, que es relevante y que se podría comparar con el papel importante que tenía la ermita en Solitud, es el de la casa paterna. Deledda refleja en ella la sociedad sarda, siendo el centro de esa sociedad y de la familia, como ocurría en la Edad Media con el castillo o el palacio del señor, pues de allí parte todo lo relacionado con la economía y el poder. El modelo sardo es el de una sociedad aún feudal donde existe una relación de amo/siervo, relación que tiene como centro la casa del señor, significado que aquí se proyecta sobre el ámbito centrado en torno a la casa patriarcal.

En este sentido, ese espacio es importante no sólo por ser el centro de la familia y de su economía, sino por ser núcleo simbólico de la autoridad paterna. Pero además, como explica la autora, con la muerte del padre se romperá el con- 
cepto de autoridad, pues los hermanos no la ejercerán. Santus se consumirá en su locura y será encerrado en la Almazara y Andrea no conseguirá ejercer el control de la familia como hiciera su padre. En definitiva, la casa - ayer espacio del orden- se convierte en un caos, del cual Cosima intenta evadirse a través de su estancia en la viña o con su marcha final de la ciudad insular a la capital romana. En el caso de Solitud, Mila se aleja de la ermita, empieza a comprender todo aquel mundo mediante las conversaciones con el Pastor. Pero la diferencia entre las dos novelas la tenemos en que cada una de las protagonistas inicia su marcha desde el eje predominante en el relato, de acuerdo con lo dicho, Mila desde el eje vertical y Cosima desde el horizontal. A continuación podemos contemplar el texto con la descripción que realiza la autora de la casa paterna:

"La casa era semplice, ma comoda: due camere per piano, grandi, un po" basse, coi pianciti e $i$ soffitti di legno; imbiancate con la calce; l'ingresso diviso in mezzo da una parete: a destra la scala, la prima rampata di scalini di granito, il resto di ardesia; a sinistra alcuni grandini che scendevano nella cantina. Il portoncino solido, fermato con un grosso gancio di ferro, aveva un battente che picchiava come un martello, $e$ un catenaccio e una serratura con la chiave grande come quella di un castello. La stanza a sinistra dell' ingresso era adibita a molti usi,con un letto alto e duro, uno scrittoio, un armadio ampio, di noce, sedie quasi rustiche, impagliate, verniciate allegramente di azzurro: quella a destra era la sala da pranzo, con un tavolo di castagno, sedie come quelle altre, un camino col pavimento battuto. Null'altro. Un uscio, solido pur esso e fermato da ganci e catenacci, metteva nella cucina. E la cucina era, come in tutte le case ancora patriarcali, l'ambiente piú abitato, piú tiepido di vita e d'intimità.

C'era il camino, ma anche un focolare centrale, segnato da quattro liste di pietra: e sopra, ad altezza d' uomo, attaccato con quattro corde di pelo alle grosse travi del soffitto di canne annerite dal fumo, un graticciato di un metro quadrato circa, sul quale stavano quasi sempre, esposte al fumo che le induriva, piccole forme di cacio pecorino, delle quali l' odore si spandeva tutto intorno. E attaccata a su volta a uno spigolo del graticciato, pendava una lucerna primitiva, di ferro nero, a quattro becchi; una specie di padellina quadrata, nel cui olio allo scoperto nuotava il lucignolo che si affacciava a uno dei becchi. Del resto tutto era semplice e antico nella cucina abbastanza grande, alta, bene illuminata da una finestra che dava sull orto e da uno sportello mobile dell' uscio sul cortile. Nell' angolo vicino alla finestra sorgeva il forno monumentale, col tubo in muratura e tre fornelli sull orlo: in un bracere accanto a questi si conservara, giorno e notte accesa e coperta di cenere, un po' di brage, e sotto l' acquaio di pietra, sotto la finestra, non mancava mai, in una piccola conca di sughero, un po' di carbone.» (pp. 3-4; tr. p. 47-48).

Como hemos visto en esta descripción de la casa se destaca como importante una de sus dependencias que es a su vez aglutinador de unas fuerzas particulares. Nos referimos a la cocina, lugar común familiar y donde mejor se reflejan los usos y las costumbres. "Aquí, en la cocina de Cosima, como en

$"$ Véase a propósito de este asunto el punto 3. 6. 1: Marco Antropológico (pp. 102-119) de la tesis de M. ${ }^{a}$ E. Arteaga Iriarte: Estudio de la narrativa de Grazia Deledda. Aproximación comparativa a Emilia Pardo Bazán y Víctor Català, UCM, 1995. 
Solitud, es donde se da rienda suelta a la imaginación y a la narración de cuentos, donde se dan a conocer las creencias del pueblo. A diferencia de Víctor Català, Deledda no intercala ningún relato breve en la narración, pero menciona que en la cocina, Nanna, la vieja criada, narra historias a los niños. La cocina, y casi siempre en torno a su perpetuo fogón, guarda una atmósfera de oracularidad y, con el tiempo, de espacio propio de la cultura femenina.

El eje vertical en Cosima, siempre más reducido, lo tenemos evidenciado fundamentalmente en dos momentos; uno en su vertiente puntual de subida a la ermita y el otro en ia contraria, mediante el descenso hacia la costa. En el instante de ascensión la autora está uniendo dos mundos que son muy importantes en la sociedad y la cultura sardas, el mundo profano y el cristiano. Es decir, se une en la subida de Cosima y de su familia hacia aquella ermita, el doble código de creencias representado respectivamente por una romería a la Virgen del Monte y por la visita a la Tumba del Gigante.

En esa ascensión se producen dos paradas, la primera es en la Tumba del Gigante. Allí según una leyenda, reposa el cuerpo del último gigante guardián del bosque. Es un monumento megalítico perteneciente a la civilización nurágica. ${ }^{12}$ Recibe este nombre por unas construcciones en forma de cono truncado, formadas por grandes bloques irregulares de piedra. Estas edificaciones hacen pensar en principio en los no menos inquietantes «talaiots» baleáricos. Al igual que estos, fueron considerados, parece ser que erróneamente, como monumentos fúnebres - como se podrá ver en la cita posterior, donde Deledda cree en este supuesto y la tradición folclórica también-, y hoy día se les tiene por fortificaciones habitadas y almacenes, con funciones religiosas e industriales.

Es natural que tales ciclópeas construcciones hayan excitado la fantasía de los habitantes más modernos de la isla, y que las nurugas, llamadas poéticamente por los sardos «domus de jana» (casa de hadas) o «tumbas de gigantes», desempeñen un importante papel en el mundo legendario, y que la fantasía popular vea en ellos los restos de un antiguo pueblo de gigantes, que las levantaron para custodia de ingentes tesoros todavía no hallados. En este espacio, Cosima, y Deledda a través de la narración, funden sus sentimientos con el espacio: «...e le sembrava davvero, riprendendo a salire il sentiero tra le felci e le chine già morbide di capelvenere e di sottilissime erbe di montagna, all ombra dei grandi elci patriarcali, di evadere dal suo piccolo mondo e ritrovarsi fra i giganti che vivono rasente al cielo, compagni dei venti, del sole e degli astri.» (p. 70; tr. p. 109). Leamos las líneas dedicadas a aquella primera parada:

«La prima sota, breve, fatta non per stanchezza ma per divertimento, fu al cominciare del bosco fitto, sotto una strana pietra poggiata su altre e detta la 'tomba del gigante'. Sembrava una grande bara, di granito, coperta da un drappo di musco, solenne nella vasta solitudine del luogo. Un tempo, diceva la leggenda, i giganti abitavano la montagna: uno di essi, a turno, vigilav'a l' ingresso della foresta; e uno di essi, l' ultimo, si stese per morire sulla pietra di confine, che si richiuse su di lui e ancora custodisce il suo corpo. Era davvero,

12 Vid. prólogo de M.a T. Navarro Salazar: Cósima, Madrid, Espasa-Calpe, 1983, pp. 27-31, o asimismo el prólogo de J. M. Velloso: Obras escogidas, Madrid, Aguilar, 1963, vol. I, pp. 17-18. 
quello, l'ingresso al mondo degli eroi, dei forti, di quelli che non possono concepire pensieri meschini; e Cosima toccò il masso, come in altri luoghi, pervasi di leggende sacre, si tocca la pietra dove queste affermano si sia riposato qualche santo.» (p. 70; tr. p. 108).

La segunda parada es ante un manantial de agua, «...pura e luminosa come il diamante» (p. 70; tr. p. 108). La autora realiza una descripción de este lugar que nos muestra el esplendor de la naturaleza y nos constata una vez más la importancia que da a estos espacios abiertos e idílicos a lo largo de la novela.

«... fu alla sorgente d'acqua pura e luminosa come il diamante, che scaturiva in una piccola conca di pietre e si spandeva modesta e quasi furtiva fra l' erba calpestata e fangosa, in un cerchio di lecci qua e là arrampicati sulle cime azzurre. Già si sentiva il grido delle ghiandaie, e l'aria sembrava un liquore profumato di menta» (pp. 70-71; tr. p. 109).

Como ocurre en la anterior parada, Cosima comulga con el espacio a través de su mirada, sentido que también sabemos muy potenciado en el caso de Mila: «...i suoi occhi, che le parvero della stessa miracolosa luce: luce che scaturiva dalla profondità della sua terra e aveva un giorno riflesso davvero l'anima assetata di divinità dei suoi avi pastori e poeti.» (p. 71; tr. p. 109)

La ermita en la obra de Deledda se encuentra en la cima de la montaña, al final de aquel camino, y el relato no sólo la utiliza como lugar sagrado sino que también la emplea como un lugar idílico, convirtiéndolo en un particular locus amoenus, equivalente a otros lugares de íntima escapada por parte de Cosima como la viña:

«... fra boschi di lecci e rocce di granito (...) sorgeva una piccola chiesa detta appunto della Madonna del Monte, su uno spiazzo sollevato e recinto di massi. Piccole stanzette erano addossate alla chiesa, sotto lo stesso tetto, e una specie di portichetto si apriva davanti alle due porte, una a mezzodi l'altra a ponente, con sedili in muratura tutto intorno.» (p. 69; tr. p. 107).

Pero no sólo está presente así como espacio religioso sino también como lugar de amor, «...era lo sfondo stesso della Poesia» (pp. 73-74; tr. p. 112)

De esta ascensión a la ermita por Cosima, podemos encontrar paralelismos en Solitud. Aunque no quisiéramos forzar mucho la comparación, cabría pensar en la ascensión al Cimalt por Mila. En Català, desde el inicio de esa ascensión, encontramos ya un reconocimiento simbólico del paisaje como se puede observar en el pasaje siguiente:

«Les primeres llü̈ssors del jorn començaven a caure imperceptiblement com una polsina suavísima, i sa mateixa vaguetat, més que les plenes tenebres, farcia el bosc de sospites $i$ recels. (...), precipitant-se barroerament cap al pastor.» (pp. 226-227: 147-174; tr. p. 128).

Tenemos en este caso una visión melancólica del paisaje, pero en otros momentos de la obra, la mirada de Mila, antes mencionada, nos presenta la naturaleza con un cierto tremendismo: 
«La Mila no es pogué estar d'aturar-se un mica per a contemplar aquell escorxament implacable: (...) d'un lloc privat on es feien coses d'aquelles que no s' han de veure» (pp. 158-159: 174-215; tr. p. 81).

También encontramos en Mila la fusión del espacio contemplado con la propia mirada antes destacada, en otros momentos de la ascensión como se puede comprobar en el fragmento transcrito a continuación:

«La Mila, novament inquietada per una sensació estranya d'ofegament, arrapava les mirades pels rebrolls, florits de blancs degotalls, i les pujava amunt, amunt, fins a trobar el velari tèrbol del firmanent. Arran d'aquella gaia de seda unida i sense llustre encara, hi percebé, tot d' una, com una fosforescència sonorosa, un xeriqueig seguit $i$ bellugadís que semblava suspès enlaire, planant lleugerament sobre el Coll de Sant Ponç i sense força per a aplomarse esquerda avall» (p. 228: 208-217; tr. p. 129).

Y para finalizar con esta breve aproximación a sendas ascensiones, también tenemos paradas puntuales en la subida, permitiendo ver a sus protagonistas el paisaje que les rodea y fundirse con él. A Mila la alecciona sobre los secretos de la naturaleza y de su vida; mientras que en Cosima la ascensión a la ermita le permite, como ya hemos indicado, fundir dos mundos, el católico y el pagano.

Como se ha advertido anteriormente, en el segundo título el descenso también se produce, como en Solitud, por un deseo de cambio. Pero no hay una situación dramática que desencadene la transformación, sino que existe un creciente deseo que se expresa a lo largo de la novela, un latente deseo de cambio en su vida, mediante el viaje a otra ciudad, hacia la llanura, a la costa, paso previo para lograr su sueño, Roma: con la llegada a un nuevo lugar, la protagonista se encontrará con una nueva sociedad. Como ocurre en la obra de Català, el cambio de una sociedad rural hacia una sociedad urbana - aquí «la planúria» vs. «la muntanya»-, es el que facilita la aparición de una nueva personalidad, una ruptura con todo lo anterior, con toda una tradición que de una u otra manera ha operado sobre las protagonistas. Leamos el siguiente texto de Deledda:

"A misura che si scendava verso le pianure marine il clima mutava completamente: si era ancora come ai primi di autunno, laggiú; il cielo, sgombro di nuvole, si faceva chiaro, verdognolo, d' un tratto Cosima lo vide riflesso in uno specchio d'acqua che le ricordò la vasca della vigna: era uno stagno. Uccelli mai veduti, grandi, con le ali iridate, si sollevarono dallo stagno, come sgorgassero dall' acqua, e disegnarono sul cielo una specie di arcobaleno: forse era un miraggio: ma a lei parve un lieto auspicio.» (p. 129; tr. p. 162).

Por su parte, el viaje - que no es en realidad una noción espacial, pero sí comporta a la vez espacialidad y temporalidad-, es un elemento común en las dos obras aquí revisadas. Es decir, el viaje en el sentido trascendente de ascensión y de descenso que encierra en su recorrido la catarsis de los personajes que lo ejecutan. La noción de viaje durante este ciclo histórico-literario, se expresa mediante la estructura e intención del Bildungsroman, es decir, enlazando el viaje y la novela de iniciación. Ese viaje de alcance iniciático está muy tipificado y su presencia en la literatura es patente desde muy antiguo. Recordemos necesa- 
riamente que el viaje ha sido para la humanidad un hecho trascendente y en especial cuando se encamina hacia espacios míticos como Oriente en el caso, por ejemplo, de la literatura medieval. Se trata de una realización del ansia de aventura del ser humano que va buscando desde siempre las tierras donde nace el sol. Por ejemplo en Solitud, el viaje es importante, ya que del camino hacia la montaña, a la ermita, se pasa a ascender a la cumbre, el Cimalt, más cerca del cosmos, donde a través del Pastor será revelada la verdad a Mila. Y en Cosima, si el viaje no se asocia necesariamente con el sol, sí se puede identificar simbólicamente el horizonte solar con la plenitud de Roma, la cual es el sueño dorado de Cosima.

Como dice Jordi Castellanos, a propósito del Bildungsroman y en función de Solitud, se da en ese modelo de discurso narrativo un «...doble itinerari: el geogràfic, extern, que porta la protagonista al coneixement de la realitat, $i$ el personal, intern, que la porta al coneixement d' ella mateixa. Aquesta duplicitat, però, s'integra en una forma novel-lística clàssica, la del viatge iniciàtic, que es realitza a través d'un cicle espacial o d'ascens i de descens de la muntanya». ${ }^{13}$ Pensamos que, de alguna manera ese juicio también se puede aplicar a Cosima, aunque no haya una nítida ascensión transformadora. Aún teniendo presente esa carencia, en nuestra opinión sí cabe hablar de Bildungsroman en este segundo título.

\section{Edición de textos}

- Català, Víctor, Solitud, edició crítica de N. Nardi, Barcelona, Edicions 62, 1990 (cit. por páginas y línea)

- Deledda, Grazia, Cosima, introduzione e bibliografia a cura di V. Spinazzola, note di A. Baldini, Milano, Arnaldo Mondadori Editore, 1989 (cit. por páginas).

\section{Traducciones: ${ }^{14}$}

- Català, Víctor, Soledad, traducción de B. Losada, prólogo de B. Porcel, Barcelona, Enciclopèdia Catalana-Alianza editorial, 1986.

- Deledda, Grazia, Cósima, introducción, traducción y notas de M. ${ }^{a}$ T. Navarro Salazar, Madrid, Espasa-Calpe, 1983.

13 En «Solitud, novel-la modernista», Els Marges, 25, 1982, p. 45.

14 Añadimos a la cita del texto original, y tras la abreviatura tr., la página de su correspondencia en las respectivas ediciones traducidas. 